\title{
Análisis de los indicadores de desarrollo humano, marginación, rezago social y pobreza en los municipios de Chiapas a partir de una perspectiva demográfica
}

\author{
Analysis of indicators of human \\ development, marginalization, social \\ backwardness and poverty in the \\ municipalities of Chiapas from a \\ demographic view
}

Óscar Peláez-Herreros*

\begin{abstract}
This paper is based on the idea that development is a multidimensional process that involves progressive changes in the economic, social and demographic features of the populations. It is argued that age structure, gender distribution, ethnic composition, size and density of populations can be relevant characteristics related to poverty and lack of development. A cross-sectional analysis, using data from the state of Chiapas at the municipal level, shows that age structure and ethnic composition are strongly related to indicators of human development, marginalization, social backwardness and poverty.
\end{abstract}

Keywords: development, age structure, ethnic composition, Chiapas.

\section{Resumen}

En este artículo se parte de la idea de que el desarrollo es un proceso multidimensional que implica la modificación progresiva de las características económicas, sociales y demográficas de las poblaciones. Se argumenta que la estructura de edades, la distribución por sexos, la composición étnica, el tamaño, así como la densidad de las poblaciones pueden ser características relevantes relacionadas con la pobreza y la falta de desarrollo. Mediante un análisis de corte transversal, utilizando datos para el estado de Chiapas en el ámbito municipal, se comprueba que la estructura de edades y la pertenencia étnica guardan una fuerte relación con los indicadores de desarrollo humano, marginación, rezago social y pobreza.

Palabras clave: desarrollo, estructura etaria, composición étnica, Chiapas.

*El Colegio de la Frontera Norte, México. Correo-e: opelaez1@gmail.com, opelaez@colef.mx. 


\section{Introducción}

Chenery y Syrquin (1975) plantean que el desarrollo no sólo implica crecimiento económico, sino también cambios en las estructuras productivas y sociales, así como en los procesos de acumulación y de asignación de recursos. Entre esos cambios estructurales que acompañan y refuerzan el crecimiento acumulativo de la renta per cápita (Myrdal, 1979) se encuentran la urbanización y la transición demográfica. Como se expone a continuación, la reducción de la fecundidad y el aumento de la esperanza de vida que tienen lugar durante el proceso de cambio demográfico alteran de manera irreversible la composición por edades de la población, lo que da lugar a una estructura etaria más favorable al crecimiento económico y a la adopción de ciertas prácticas que refuerzan el desarrollo. A esta dinámica se suman otras características que pueden favorecer o lastrar el progreso de las poblaciones. La emigración, por ejemplo, al ser en su mayor parte masculina en el caso de México, es posible que también afecte las posibilidades de desarrollo, dada la diferente contribución que hombres y mujeres realizan a la producción. Asimismo, la composición étnica puede resultar un factor relevante considerando el limitado acceso que, por diversos motivos, ciertos grupos indígenas tienen a medios de producción, centros de salud, etcétera (CDI-PNUD, 2006). Otras características, como el tamaño o la densidad de las poblaciones, también pueden tener incidencia a través de las economías de escala que, por ejemplo, suponen menores costos relativos para la dotación de infraestructuras públicas (Livi-Bacci, 2002: 130-135).

Una vez descritos en detalle estos mecanismos, se analiza la situación particular de los municipios de Chiapas con el objetivo de ver la relación que existe entre sus características demográficas y los niveles de desarrollo, marginación, rezago social y pobreza de sus pobladores. Con ello se pretende develar algunas claves del escaso grado de desarrollo que se observa en ciertas zonas del estado y, a partir de ese conocimiento, evaluar las medidas de política pública que se han aplicado en los últimos años. Todo ello se estructura en cuatro apartados: en el primero se presentan los fundamentos teóricos que sustentan las hipótesis de trabajo; en el segundo la metodología de análisis; en el tercero la evidencia empírica para los municipios de Chiapas; y en el cuarto, las conclusiones que se obtienen del análisis propuesto.

\section{Implicaciones de ciertas características demográficas sobre la capacidad de desarrollo y crecimiento económico}

En el régimen demográfico antiguo, la muerte era un fenómeno habitual que impedía que un tercio de los nacidos alcanzara la edad adulta. La 
falta de higiene, la escasez de alimentos en los años de mala cosecha o el desconocimiento de las causas y del tratamiento de las distintas enfermedades hacía que cada año falleciese entre 3 y $4 \%$ de la población. Para compensar esa elevada mortalidad, la fecundidad también presentaba un valor muy alto, en torno a los seis hijos por mujer.

Las condiciones de vida comenzaron a cambiar a partir de las revoluciones agrícola e industrial que tuvieron lugar en Inglaterra durante los siglos XVII y XVIII (Notestein, 1945: 39). Las mejoras en la higiene y en la nutrición evitaron un buen número de fallecimientos, sobre todo entre la población más joven. El posterior desarrollo de la medicina y la difusión por toda la sociedad de los distintos avances y de los nuevos hábitos más saludables reforzó esa tendencia. En un principio, el comportamiento reproductivo de la población tardó en adaptarse a las nuevas condiciones de menor mortalidad, pero, tras unas décadas de retraso, la tasa de natalidad también comenzó a reducirse (Vallin, 1995: 69).

Estos cambios, que se iniciaron en Inglaterra, se fueron extendiendo al resto de poblaciones, aunque con diferencias notables en los calendarios e intensidades. Así, cuando Notestein (1945) describe la teoría de la transición demográfica, ya esbozada por Thompson (1929), divide a los distintos países en tres estadios sucesivos que conducen desde el régimen demográfico antiguo (en el que las tasas de mortalidad y de natalidad son altas, en torno a $40 \%$ ) al régimen demográfico moderno (en el que ambas tasas tienden a igualarse en niveles bajos, alrededor de 10\%). En el último de esos tres estadios, cuando la mayor parte de la población sobrevive hasta edades avanzadas y la fecundidad se iguala o incluso cae bajo el nivel de reemplazo generacional, la estructura de edades de la población se comienza a transformar. Las nuevas cohortes presentan un tamaño semejante al de sus progenitoras y apenas pierden miembros con el transcurso del tiempo debido a que la mortalidad es muy reducida. La baja natalidad hace que la pirámide se estreche por la base y la escasa incidencia de la mortalidad, que apenas actúa hasta la vejez (Fries, 1980), provoca su ensanchamiento en la cima (figura I), ya que cada vez sobrevive más gente durante mayor tiempo. De este modo, primero se reduce el porcentaje de jóvenes y aumenta el tamaño relativo de la población en edad de trabajar, y luego, también, se incrementa el porcentaje de ancianos dada la mayor capacidad de supervivencia.

Esta transformación afecta la capacidad de crecimiento económico medido a través del PIB per cápita (el producto interno bruto dividido entre la población), ya que no todos los estratos de edad aportan lo mismo al piB mientras que sí cuentan igual para el cómputo de la población. Como observa Mason (2007: 83) para la economía estadounidense, los jóvenes no contribuyen a la producción hasta que se incorporan al mer- 


\section{Figura I}

Cambios en la estructura de edades de la población durante la transición demográfica

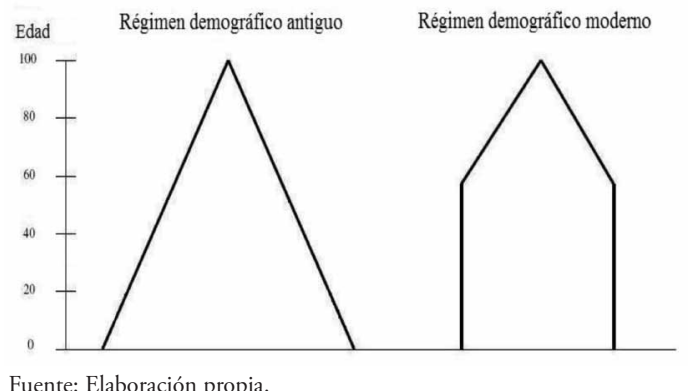

cado de trabajo y, además, consumen poco, pero aun así, más de lo que producen, lo que les lleva a desahorrar como plantea la teoría del ciclo vital del ahorro de Modigliani (1986). Algo parecido ocurre con los mayores. Al retirarse del mercado de trabajo, su aportación a la producción se reduce: cae por debajo de su nivel de consumo. La población en edad de trabajar es la que contribuye en mayor medida a la producción, que luego el pIB per cápita se encarga de repartir por igual, de forma artificial, entre todos los habitantes del territorio que se esté considerando.

En una población donde predominen los jóvenes existen muchas bocas por alimentar respecto a las manos que trabajan (Coale y Hoover, 1958), de modo que la producción total a repartir tenderá a ser menor que en otra población donde abunden las personas en edad laboral. Evidentemente, un elevado porcentaje de población en edad de trabajar no garantiza que el рів per cápita sea alto. Además de existir, esa población tiene que participar en el proceso productivo. Por ello, no se puede olvidar la relevancia de la tasa de empleo, que indica cuántos de los que están en edad de trabajar se encuentran realmente desarrollando alguna actividad. Asimismo, hay que tener en cuenta que no todos los trabajadores generan un volumen de producción ni siquiera semejante, por lo que la productividad del trabajo también se debe considerar. Estas relaciones se recogen en la descomposición factorial planteada por Bloom et al. (2000) que permite expresar el pIB per cápita como el producto del tamańo relativo de la población en edad de trabajar, la tasa de empleo y la productividad:

$$
\text { PIB per cápita }=\frac{P I B}{\text { población }}=\underbrace{\frac{p o b(15-64)}{\text { población }}}_{\begin{array}{c}
\text { Peso de la población } \\
\text { en edad de trabajar }
\end{array}} \underbrace{\frac{\text { núm. ocupados }}{\text { pob(15-64) }} \underbrace{\frac{\text { PIB }}{\text { núm. ocupados }}}_{\text {Productividad }}}_{\text {Tasa de empleo }}
$$


Con este planteamiento, cabría esperar que aquellas poblaciones que se encuentran en un estadio menos avanzado de la transición demográfica, que todavía presentan una estructura de edades con forma piramidal y que, por tanto, disponen de un menor porcentaje de población en edad de trabajar, muestren también un PIB per cápita más bajo. Pero no sólo por este motivo, que puede considerarse que actúa de forma directa en la producción. Indirectamente, una fecundidad elevada dificulta la incorporación de las mujeres al mercado formal de trabajo, lastrando la tasa de empleo, pero también obstaculiza el aumento de la productividad al ser pocos los recursos que se invierten en la formación de cada uno de los numerosos hijos que se tienen (Becker, 1987). Una tasa de fecundidad alta tiende a actuar de forma negativa sobre cada uno de los tres factores que componen el PIB per cápita.

Como advirtieron Chenery y Syrquin (1975), el proceso de transición demográfica, esto es, el descenso de las tasas de natalidad y mortalidad que provoca el cambio estructural en la distribución por edades de la población, está ligado al crecimiento económico y, ambos, al desarrollo. Al mismo tiempo, el cambio demográfico es causa, como se desprende de la descomposición anterior, y efecto de la expansión del PIB per cápita, ya que el aumento de la riqueza genera los incentivos para la reducción de la natalidad (Coale, 1988) y sostiene el avance de las condiciones de vida y de las mejoras sanitarias que impulsan el descenso de la mortalidad.

Esta situación se corresponde con la hipótesis de causación circular planteada por Myrdal: "Normalmente, un cambio no da lugar a cambios compensadores, sino que, por lo contrario, da lugar a cambios coadyuvantes que mueven al sistema en la misma dirección que el cambio original, impulsándolo más lejos. Esta causación circular hace que un proceso social tienda a convertirse en acumulativo" (1979: 24). Myrdal (1979: 23) advierte que la acumulación se puede dar en sentido positivo, a modo de espiral ascendente, pero también en sentido negativo, como círculo vicioso. La modificación de la estructura etaria, en su dinámica e interacción con el crecimiento económico y con la productividad de los trabajadores a través de la educación, se presenta como uno de estos factores fuertemente ligados a la causación circular. En una población con una tasa de natalidad alta, donde cada familia tiene un número elevado de hijos, la inversión que se realiza en la educación de cada hijo tiende a ser baja (Becker, 1987). Los hijos son vistos como fuente de ingreso a corto plazo, se les incorpora desde temprana edad a la actividad productiva, generalmente, ligada al sector primario. ${ }^{1}$ Con ello se com-

\footnotetext{
${ }^{1}$ En Chiapas, el trabajo infantil en la industria no es frecuente debido al escaso desarrollo de este sector en la región. En los municipios más urbanos los hijos se pueden utilizar como mano de obra gratuita y puestos a trabajar en el sector terciario en la venta de productos. No obstante, en las
} 
pensa, en parte, la escasez de trabajadores, pero se limita sustancialmente la posibilidad de crecimiento de la productividad. En esa situación, el PIB per cápita tiende a permanecer estancado en niveles bajos. No se registran cambios en sentido positivo, ya que la incorporación de los jóvenes al mercado de trabajo restringe su formación limitando sus posibilidades futuras. De esa forma, las sucesivas generaciones quedan atrapadas en un círculo vicioso que las condena a continuar con la actividad productiva familiar y a reproducir las mismas estrategias de sus progenitores: alta fecundidad, escasa educación, baja productividad y, de nuevo, necesidad de tener muchos hijos y de incorporarlos pronto a la actividad laboral en un intento por compensar la baja productividad y el escaso ingreso asociado a ella. ${ }^{2}$

En las actuales sociedades desarrolladas esta trampa fue desapareciendo con la industrialización y el surgimiento de nuevos empleos. Como señala Davis (1937), el desempeño de los trabajos que aparecen con la industrialización y la posterior terciarización de la economía requiere una educación especializada que no puede facilitar la familia. La escolarización se hace necesaria para aprovechar las ventajas que brindan estos empleos. Como la educación es costosa, tanto en términos directos como por los lucros cesantes, los progenitores se ven obligados a reducir el tamaño de su descendencia. Los hijos dejan de ser vistos como una fuente de ingreso a corto plazo para convertirse en una inversión a largo plazo, lo que representa un gasto a corto plazo. En las sociedades con algún grado de modernización, surgen incentivos para sustituir cantidad por calidad en los hijos (Becker y Lewis, 1973; Becker, 1987; Becker et al., 1999; Galor y Weil, 1999, 2000). Con ello las nuevas generaciones están mejor educadas, lo que ayuda a elevar la productividad y acelera el proceso de desarrollo a modo de espiral virtuosa en la que se interrelacionan variables económicas, sociales y demográficas cuyos progresos se van reforzando mutuamente.

Además de la estructura de edades, existen otras características demográficas que pueden tener efectos positivos o negativos en las posibilidades de desarrollo de las poblaciones. La distribución por sexos, la presencia en una región de un número más elevado de hombres que de mujeres, o viceversa, puede limitar no sólo la capacidad de crecimiento económico sino también el desarrollo, entendido en su sentido amplio, dada la especialización por género y la diferenciación de tareas que se observa tanto en el mercado laboral como en el interior de las unidades domésticas. La

zonas urbanas, las posibilidades de educación y de acceso a un mejor empleo son mayores, lo que eleva los incentivos para contener la natalidad e invertir en la educación de los hijos, como se ve a continuación.

${ }^{2}$ Según CDI-PNUD: "El factor que más influye en la desigualdad social es la educación, debido a que dependerá de la calificación y capacitación laboral del individuo, el posicionamiento que tendrá en la escala de la distribución del ingreso" (2006: 274). 
emigración masculina hacia ciertas regiones de México y, especialmente a Estados Unidos, ha provocado que, según el II Conteo de Población y Vivienda 2005, el número de hombres supere al de mujeres en sólo cuatro entidades del país: Baja California, Baja California Sur, Quintana Roo y Sonora. La emigración laboral ha llevado a que en Guanajuato, Michoacán y Oaxaca resida casi $10 \%$ más de mujeres que de hombres. En el ámbito municipal se observan desplazamientos complementarios, principalmente, desde el ámbito rural al urbano, debidos a la población femenina que busca emplearse en el sector terciario. Todo ello ha dado lugar a desequilibrios importantes en la distribución por sexos de la población residente en ciertas regiones del país, lo que puede estar condicionando sus posibilidades de desarrollo.

Como se desprende del informe CDI-PNUD (2006: 78), la pertenencia étnica también se presenta como un factor relevante a la hora de explicar las condiciones de pobreza y falta de desarrollo en algunas poblaciones. Así, mientras que el índice de desarrollo humano (IDH) alcanza un valor de 0.8304 para los residentes no indígenas de México, para los pueblos indígenas, considerados de manera conjunta, toma un valor de 0.7057 , con cifras mínimas entre los indígenas de la Montaña de Guerrero (0.6184), las Chimalapas (0.6219) y la Selva Lacandona (0.6264) (CDI-PNUd, 2006: 177). El acceso limitado - por motivos históricos, culturales y geográficosde estas poblaciones a los medios de producción o a las instituciones de salud, educación o justicia, restringe su capacidad para escapar de la pobreza, hecho que se percibe a través de la condición étnica.

Otras características, como el tamaño o la densidad de las poblaciones, también pueden ser factores condicionantes de los niveles de desarrollo y pobreza. Así, por ejemplo, la concentración de población en núcleos urbanos favorece la dotación de infraestructuras públicas que, con los mismos costos fijos, benefician a un mayor número de personas (LiviBacci, 2002: 130-135). Sin embargo, densidades de población altas también pueden dar lugar a una escasez relativa de recursos, principalmente en zonas rurales donde la tierra, como elemento esencial de producción, es un factor limitado.

Para estudiar las relaciones entre las características demográficas comentadas y el crecimiento económico, el desarrollo, la marginación y la pobreza, en el siguiente apartado se describe una metodología que permite comprobar el cumplimiento de estas hipótesis.

\section{Metodología de análisis}

Como se ha expuesto, el proceso de desarrollo se debe ver a partir de una perspectiva multidimensional, ya que implica la modificación simultánea 
de un buen número de variables estructurales que acompañan y refuerzan el crecimiento acumulativo de la renta per cápita. La transición demográfica, la progresiva alteración de los patrones reproductivos y de mortalidad que modifican la estructura de edades, las migraciones que desequilibran la distribución por sexos de la población, la concentración de residentes en un área geográfica, o la pertenencia étnica son factores con potencial para interactuar con los mecanismos que impulsan la mejora de las condiciones de vida.

Para estudiar la intensidad de la relación que mantienen estas características demográficas con los niveles de desarrollo y pobreza, se plantea un análisis de corte transversal en el ámbito municipal en el estado de Chiapas con datos de 2005, año en el que se dispone de información para todas las variables que se consideran en el estudio. Los indicadores demográficos se calculan a partir de los datos del II Conteo de Población y Vivienda 2005 (INEGI, 2005). Entre estos indicadores se encuentra la composición por edades de la población que, medida a través del porcentaje de población en edad de trabajar, sirve para aproximar la etapa del proceso de transición demográfica en que se encuentra cada municipio. Teniendo en cuenta los planteamientos teóricos presentados en el apartado anterior, cabría esperar que aquellos municipios con menor tamaño relativo de población en edad de trabajar, menos avanzados en el proceso de transición demográfica, muestren niveles de desarrollo más bajos y de pobreza más altos.

Además de la estructura de edades, también se consideran otras características geodemográficas de la población residente en los distintos municipios de Chiapas, como la distribución por género, medida a través del índice de masculinidad; ${ }^{3}$ la composición étnica, vista a partir del porcentaje de población que habla alguna lengua indígena; ${ }^{4}$ el tamaño de la población, medido como el número de residentes en cada municipio; y la densidad, esto es, el número de habitantes por kilómetro cuadrado. ${ }^{5}$

${ }^{3}$ El índice de masculinidad se calcula como el número de hombres residentes en un territorio dividido entre el número de mujeres correspondiente.

${ }^{4} \mathrm{La}$ información sobre el porcentaje de población que habla alguna lengua indígena se obtuvo de la sección "7. Cultura y deporte" del InEgi (2008). Como señala la CDI-PNud, "la lengua se constituye en un instrumento útil para identificar a la población indígena, sin embargo la limitación del universo indígena a la población que habla lengua indígena puede ser una restricción con importantes consecuencias" (2006: 64). Aun con estos inconvenientes, dada la disponibilidad de información sobre la población que habla lengua indígena, el tratamiento que se pretende realizar con esta variable (medida en términos relativos para todos los municipios), así como la práctica habitual de asociar ambas características, se ha elegido el número de hablantes de lengua indígena como indicador del tamaño de su población.

${ }^{5}$ Para el cálculo de la densidad de población se utilizó información del INEGI (2005) en lo referente a los datos sobre población; y de la sección "2. Medio ambiente" del INEGI (2008) para los datos acerca de la superficie de los municipios. 
Como medida de las condiciones de vida se utilizan varios indicadores calculados por instituciones de reconocido prestigio y que encuentran fundamento en la literatura sobre medición de la pobreza y el bienestar, éstos son: los porcentajes de población en situación de pobreza alimentaria, de capacidades y de patrimonio, así como los índices de desarrollo humano (IDH), rezago social y marginación; ${ }^{6}$ todos ellos calculados para el año 2005. El motivo por el cual se recurre a estos seis indicadores, y no sólo a uno, es la existencia de diversas definiciones de pobreza y bienestar, que implican diferentes formas de medir estos fenómenos. Las posibles deficiencias de los indicadores mencionados, que se exponen más en detalle a continuación, limitan el alcance del presente estudio. Otras limitaciones que cabe destacar son el nivel de agregación de la información, que podría ocultar ciertas particularidades tras el cómputo de valores medios para cada uno de los municipios, y la aproximación de las características demográficas mediante las variables citadas en párrafos anteriores.

Para entender los problemas asociados a la cuantificación del bienestar conviene remontarse hasta el origen de sus procedimientos de medición. En este sentido, suele reconocerse a Charles Booth como el primer investigador que no sólo observó la pobreza, sino que también intentó medirla para elaborar mapas de esta característica en Londres entre los años 1892 y 1897 . Poco después, Rowntree (1901) desarrolló un estudio en York utilizando un concepto de pobreza basado en requerimientos nutricionales (Domínguez y Martín, 2006: 30). En ambos casos, se recurrió a la técnica de las líneas de pobreza que, en términos generales, reflejan el nivel de renta necesario para cubrir las llamadas necesidades básicas de vida (Kakwani, 1986: 239), permitiendo la clasificación de una persona como pobre bajo el único criterio de que su renta estimada sea inferior a dicho nivel. En México, de acuerdo con la Ley General de Desarrollo Social (LGDS), el Consejo Nacional de Evaluación de la Política de Desarrollo Social (Coneval) tiene la facultad y la responsabilidad de establecer los lineamientos y criterios para definir, identificar y medir la pobreza. Para cumplir esta función, el Coneval estima la pobreza mediante distintos procedimientos. Uno de ellos consiste en la definición de tres líneas de pobreza: alimentaria, de capacidades y de patrimonio; ${ }^{7}$ a partir de las

${ }^{6}$ Los porcentajes de pobreza alimentaria, de capacidades y de patrimonio, y el índice de rezago social se obtuvieron del Consejo Nacional de Evaluación de la Política de Desarrollo Social (Coneval), www.coneval.gob.mx. Los datos del índice de desarrollo humano proceden del Programa de las Naciones Unidas para el Desarrollo (PNUD), www.undp.org.mx. La información relativa al índice de marginación, del Consejo Nacional de Población (Conapo), www.conapo.gob.mx.

${ }^{7}$ Según el Coneval, se encuentran en situación de pobreza alimentaria aquellas personas que no tienen capacidad para obtener una canasta básica alimentaria, aun si hicieran uso de todo el ingreso disponible en su hogar para comprar sólo los bienes de dicha canasta. De modo semejante, la pobreza de capacidades se define como la insuficiencia del ingreso disponible para adquirir el valor de la canasta alimentaria y efectuar los gastos necesarios en salud y educación, incluso dedicando el ingre- 
cuales se computan los porcentajes de población que se encuentran en cada uno de esos niveles en las entidades federativas y municipios del país. Estos porcentajes forman parte de las variables que se utilizan en el presente estudio para analizar la intensidad de las relaciones entre características demográficas y bienestar de la población.

Como han señalado varios autores, las líneas de pobreza presentan serias limitaciones. Por ejemplo, no atienden la magnitud del déficit de ingresos de quienes están bajo el nivel de pobreza. No importa si una persona cae precisamente bajo la línea o muy lejos de ella padeciendo hambre y miseria extremos. Además, son medidas insensibles a la distribución del ingreso entre los pobres así como a las transferencias de renta de los pobres a los ricos. A ello se suma el hecho de que las líneas no sólo dependen de los patrones de vida de las sociedades particulares (Atkinson, 1974: 48), sino también de las características de los individuos ya que, por ejemplo, las necesidades nutricionales varían con la edad, el sexo, la ocupación, la actividad física o el clima (Townsend, 1979, 1993).

A principios de la década de los ochenta, una crítica más profunda, dirigida no tanto a la herramienta de medición como al concepto de pobreza implícito, llevó a la construcción de toda una nueva gama de indicadores. Sen (1983) argumentó que el nivel de vida de las personas está determinado por sus capacidades y no por los bienes que poseen ni por la utilidad que obtienen de estos. Dado que la conversión del ingreso en capacidades básicas varía de manera significativa entre individuos, debido a la edad, la localización o la epidemiología, Sen propuso definir la pobreza en términos de privación de las capacidades. Desde esta perspectiva, lo que determina el nivel de vida es la facultad de realizar acciones, así, la pobreza pasa a ser un concepto multidimensional que refleja la incapacidad de las personas de vivir una vida tolerable.

Atendiendo a esta idea, desde 1990 el Programa de las Naciones Unidas para el Desarrollo (PNUD) viene calculando el IDH para los distintos países del mundo a partir de tres parámetros esenciales: nivel de vida digno (medido por el PIв per cápita en paridades de poder adquisitivo), educación (medida por la tasa de alfabetización de adultos y la tasa bruta combinada de matriculación en educación primaria, secundaria y superior, así como los años de duración de la educación obligatoria) y vida larga y saludable (medida según la esperanza de vida al nacer). En el ámbito municipal, que es el caso que nos ocupa, el IDH conserva su estructura básica de cálculo, pero ve cómo algunas de sus variables de medición son

so total de los hogares nada más que para estos fines. Análogamente, están en situación de pobreza de patrimonio aquellos cuyo ingreso disponible no es suficiente para adquirir la canasta alimentaria, así como realizar los gastos necesarios en salud, vestido, vivienda, transporte y educación, aunque la totalidad del ingreso del hogar se utilice exclusivamente para la adquisición de estos bienes y servicios. 
reemplazadas por otras más propias para poblaciones de tamaño reducido. ${ }^{8}$ El IDH en el ámbito municipal es otro de los indicadores empleados en esta investigación.

Como se comentó, la LGDS confiere al Coneval la responsabilidad de establecer los lineamientos y criterios para definir, identificar y medir la pobreza en México. Además, exige que esta medición incorpore al menos los indicadores de ingreso corriente per cápita, rezago educativo promedio en el hogar, acceso a los servicios de salud, acceso a la seguridad social, calidad y espacios de la vivienda, acceso a la alimentación y grado de cohesión social, reconociendo la pobreza como una manifestación multidimensional de carencias. Esto hace que las líneas de pobreza que también calcula este organismo sean medidas insuficientes. Por ello el Coneval construye el índice de rezago social, incorporando indicadores de educación, acceso a servicios de salud, calidad y servicios de las viviendas, etcétera. ${ }^{9}$ De modo similar, considerando que la privación de capacidades se puede medir indirectamente a través del acceso a bienes, servicios e infraestructura, el Consejo Nacional de Población (Conapo) estima el índice de marginación. ${ }^{10}$ Ambos indicadores de necesidades básicas insatisfechas, tanto el de marginación como el de rezago social, se consideran en el estudio que se desarrolla en la sección siguiente.

Respecto a las herramientas analíticas empleadas en esta investigación, cabe comentar que se descarta la técnica de regresión, ya que la misma exige identificar al menos una variable como causa y otra como efecto, lo cual es incompatible con el marco teórico de causación circular entre variables que se han descrito. Debido a ello, se descarta también la utilización de los coeficientes de correlación lineal $(r)$, y de determinación

\footnotetext{
${ }^{8}$ Así ocurre con el indicador de nivel de vida, donde el ingreso per cápita anual sustituye al PIB per cápita; con el indicador de educación, donde la tasa de asistencia escolar se utiliza en lugar de la tasa de matriculación; y con el indicador de salud, donde la tasa de mortalidad infantil reemplaza a la esperanza de vida al nacimiento.

${ }^{9}$ Concretamente, las variables que el Coneval utiliza para calcular el índice de rezago social son los porcentajes de las 13 siguientes: población de 15 años o más analfabeta, población de 6 a 14 años que no asiste a la escuela, población de 15 años o más con educación básica incompleta, hogares con población de 15 a 29 años con algún habitante con menos de nueve años de educación aprobados, población sin derechohabiencia a servicios de salud, viviendas particulares habitadas con piso de tierra, viviendas particulares habitadas que no disponen de excusado o sanitario, viviendas particulares habitadas que no disponen de agua entubada de la red pública, viviendas particulares habitadas que no disponen de drenaje, viviendas particulares habitadas que no disponen de energía eléctrica, viviendas particulares habitadas que no disponen de lavadora, y viviendas particulares habitadas que no disponen de refrigerador, así como promedio de ocupantes por cuarto.

${ }^{10}$ Las variables que emplea el Conapo para elaborar el índice de marginación son los porcentajes de las siguientes nueve: población analfabeta de 15 ańos o más, población sin primaria completa de 15 años o más, ocupantes en viviendas sin drenaje ni servicio sanitario, ocupantes en viviendas sin energía eléctrica, ocupantes en viviendas sin agua entubada, viviendas con algún nivel de hacinamiento, ocupantes en viviendas con piso de tierra, población en localidades con menos de 5,000 habitantes, y población ocupada con ingreso de hasta dos salarios mínimos.
} 
lineal $r^{2}$, como medidas de la relación existente entre las distintas variables. Se debe tener en cuenta que, al margen del problema de causalidad, estos coeficientes únicamente indican el grado de relación lineal de las variables analizadas, cuando se están considerando algunas, como el IDH o los porcentajes de pobreza, acotados superior e inferiormente, que describen trayectorias no lineales.

Por estos motivos, para estudiar la relación entre las variables objeto de análisis, se propone utilizar el coeficiente de correlación por rangos de Spearman $(\rho)$, que se calcula mediante la expresión:

$$
\rho=1-\frac{6 \cdot \sum_{i=1}^{N} D_{i}^{2}}{N\left(N^{2}-1\right)}
$$

donde $D$ es la diferencia entre los órdenes de las dos variables consideradas, y $N$ es el número de observaciones disponibles para cada variable que, en el caso que se contempla, es igual a 118, una por cada municipio de Chiapas. El coeficiente de Spearman se interpreta del mismo modo que el coeficiente de correlación de Pearson: oscila entre -1 y +1 indicando asociaciones negativas o positivas, respectivamente, o ausencia de relación entre las ordenaciones cuando se iguala a cero.

Además de las técnicas comentadas para el análisis de la relación entre las distintas variables e indicadores considerados, también se utiliza el método de estratificación univariante propuesto por Dalenius y Hodges (1957, 1959), que permite segregar los municipios estudiados y establecer agrupaciones homogéneas que facilitan la descripción de la situación relativa de cada población.

\section{Evidencia empírica: el caso de los municipios de Chiapas}

El estado de Chiapas, al sur de México, se presenta como uno de los territorios más propicios para estudiar la relación entre las características demográficas, el crecimiento económico, la pobreza y el desarrollo, ya que en él conviven poblaciones avanzadas en su transición demográfica con otras muy atrasadas, poblaciones urbanas y rurales, ${ }^{11}$ con composiciones étnicas diversas, y además contiene municipios con valores extremos para los índices de desarrollo humano, marginación, rezago social y pobreza.

Tuxtla Gutiérrez, la capital del estado, presenta una estructura de edades que está perdiendo su forma piramidal característica (figura II). La

\footnotetext{
${ }^{11}$ Aproximadamente $58 \%$ de la población residente en Chiapas vive en localidades de menos de 5,000 habitantes. Asimismo, existen grandes núcleos urbanos como Tuxtla Gutiérrez (490,455 habitantes), Tapachula $(189,991)$ o San Cristóbal de las Casas $(142,364)$.
} 
cohorte más numerosa en 2005 es la que tiene entre 20 y 24 ańos. Las generaciones de menor edad son más reducidas. Eso hace que sólo 29\% de la población aún no haya cumplido los 15 años (cuadro 1). Tapachula, el segundo municipio más poblado y también el segundo en la clasificación del IDH, se encuentra en una situación similar, con 32\% de sus habitantes por debajo de los 15 años. Ambos municipios presentan un alto grado de feminización de su población, con índices de masculinidad de $91.78 \%$ en Tuxtla Gutiérrez y $92.72 \%$ en Tapachula, el quinto y el octavo más bajos del estado. Los porcentajes de población indígena residente también son muy reducidos: $1.86 \%$ y $0.89 \%$, respectivamente. Frente a estos casos, los municipios de Santiago el Pinar y Mitontic, los dos con el menor IDH de Chiapas, aún conservan estructuras etarias con bases muy amplias (figura II), poblaciones no tan feminizadas y porcentajes de residentes indígenas muy elevados: $99.90 \%$ y $99.75 \%$, respectivamente. Comparando sólo los municipios extremos, al parecer existe una relación clara entre presencia de indígenas, estructura de edades y escaso desarrollo humano. A continuación se comprueba si esta relación se mantiene para el resto de municipios, así como para las demás variables consideradas.

\section{Figura II}

\section{Estructuras de edades en el ańo 2005 para los municipios de Chiapas con mayor y menor IDH}
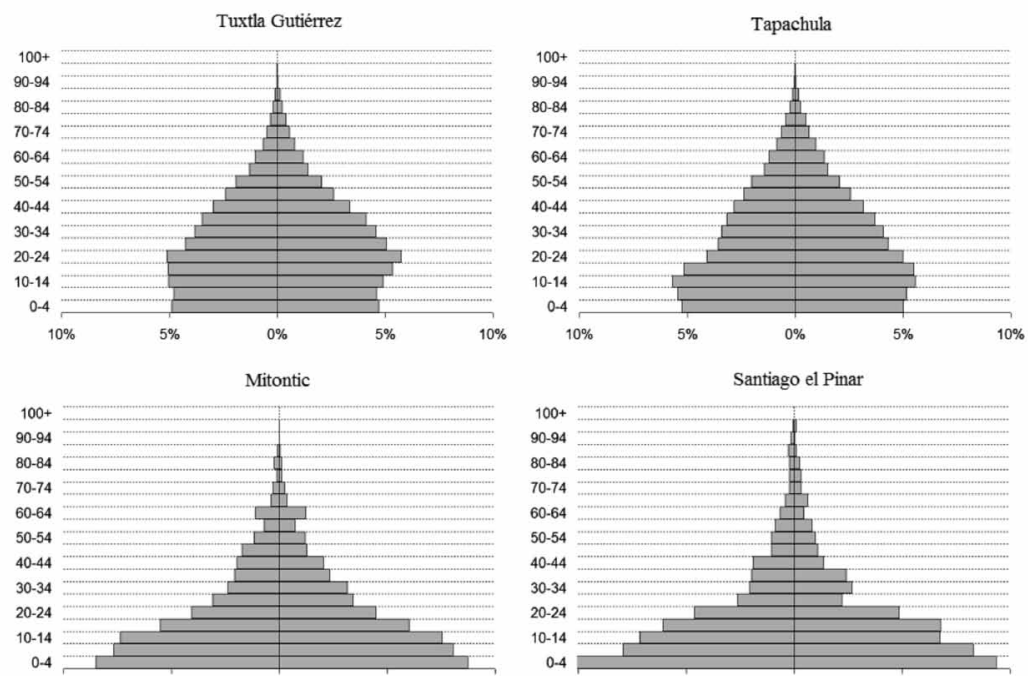

Fuente: Elaboración propia a partir de INEGI (2005). 


\section{Cuadro 1}

\section{Porcentajes de población por estratos de edad para Chiapas y los municipios con mayor y menor IDH en el ańo 2005}

\begin{tabular}{lccc}
\hline \multicolumn{1}{c}{ Población } & $0-14$ & $15-64$ & $65 y$ más \\
\hline Tuxtla Gutiérrez & 28.94 & 67.02 & 4.04 \\
Tapachula & 32.20 & 62.71 & 5.09 \\
Reforma & 33.27 & 63.08 & 3.65 \\
$\ldots$ & $\ldots$ & $\ldots$ & $\ldots$ \\
Sitalá & 45.83 & 51.98 & 2.19 \\
Mitontic & 47.93 & 49.87 & 2.20 \\
Santiago el Pinar & 49.77 & 46.76 & 3.47 \\
Chiapas & 36.95 & 58.74 & 4.31 \\
\hline
\end{tabular}

Fuente: Elaboración propia a partir de INEGI (2005).

Para medir el grado de modernización de la estructura de edades se optó por utilizar el porcentaje de población en edad de trabajar ya que, como se comentó, los cambios que ocurren durante la transición demográfica hacen que, primero, se reduzca el porcentaje de jóvenes y aumente el tamaño relativo de la población en edad laboral, para luego incrementarse también el porcentaje de ancianos a costa de la población de edad intermedia. Por ahora, en ninguno de los municipios de Chiapas se ha alcanzado esta última etapa de envejecimiento de la población propia de las naciones más desarrolladas (Peláez, 2009). Debido a ello, valores más altos del porcentaje de población en edad de trabajar aún indican un estado más avanzado en el proceso de transición demográfica. ${ }^{12}$

Como se observa en el cuadro 2, el porcentaje de población entre 15 y 64 años guarda una relación directa con el IDH e inversa con el resto de indicadores, resultando los coeficientes de correlación muy altos en todos los casos. Esto indica que los municipios con mayor proporción de población en edad de trabajar disfrutan de niveles de desarrollo humano

${ }^{12}$ Las diferencias existentes en las estructuras de edades también se podían haber medido a través del índice general de dependencia, que muestra la proporción de jóvenes y ancianos (población dependiente) respecto a la población en edad de trabajar. En ese caso, dada la definición del índice (población menor de 15 y mayor de 64 años dividida por la población comprendida entre 15 y 64 años), se hubiese obtenido una ordenación de los municipios idéntica a la generada por el porcentaje de población entre 15 y 64 ańos pero en sentido inverso, de modo que los coeficientes de Spearman hubiesen sido exactamente los mismos pero con signo contrario. De haberse utilizado el índice de dependencia de jóvenes (población menor de 15 años dividida por aquélla comprendida entre 15 y 64 años) las correlaciones apenas hubiesen variado, ya que en Chiapas el índice general de dependencia y el índice de dependencia de jóvenes generan ordenaciones muy parecidas dado que el porcentaje de mayores de 64 años es aún muy bajo en todos los municipios. Los coeficientes de correlación por rangos de Spearman hubiesen sido de -0.810 respecto al índice de desarrollo humano, 0.835 para el índice de marginación, 0.889 para el rezago social, 0.863 para la pobreza alimentaria, 0.859 respecto a la pobreza de capacidades y 0.840 para la pobreza de patrimonio. 


\section{Cuadro 2}

Valores del coeficiente de correlación por rangos de Spearman para distintas combinaciones de variables

\begin{tabular}{lccccc}
\hline & $\begin{array}{c}\text { Porcentaje de } \\
\text { población entre } \\
\text { 15 y 64 años } \\
\text { de edad }\end{array}$ & $\begin{array}{c}\text { Indice de } \\
\text { masculinidad }\end{array}$ & $\begin{array}{c}\text { Porcentaje de } \\
\text { población que } \\
\text { habla lengua } \\
\text { indigena }\end{array}$ & $\begin{array}{c}\text { Número de } \\
\text { habitantes }\end{array}$ & $\begin{array}{c}\text { Densidad } \\
\text { (habitantes } \\
\text { por } \mathrm{km}^{2} \text { ) }\end{array}$ \\
\hline $\begin{array}{c}\text { Indice de } \\
\text { desarrollo } \\
\text { humano }\end{array}$ & 0.789 & -0.160 & -0.765 & 0.312 & -0.088 \\
$\begin{array}{c}\text { Indice de } \\
\text { marginación }\end{array}$ & -0.824 & 0.198 & 0.695 & -0.308 & 0.020 \\
$\begin{array}{c}\text { Indice de rezago } \\
\text { social }\end{array}$ & -0.873 & 0.162 & 0.731 & -0.241 & 0.111 \\
$\begin{array}{c}\text { Pobreza } \\
\text { alimentaria }\end{array}$ & -0.859 & 0.001 & 0.733 & -0.135 & 0.129 \\
$\begin{array}{c}\text { Pobreza de } \\
\text { capacidades }\end{array}$ & -0.855 & -0.003 & 0.732 & -0.127 & 0.127 \\
$\begin{array}{c}\text { Pobreza de } \\
\text { patrimonio }\end{array}$ & -0.837 & -0.007 & 0.715 & -0.121 & 0.117 \\
\hline
\end{tabular}

Fuente: Elaboración propia.

más altos y de marginación, rezago social y pobreza más bajos. Los municipios peor clasificados en cada uno de los indicadores (Santiago el Pinar en desarrollo humano, pobreza alimentaria y pobreza de capacidades; Sitalá en marginación y rezago social; y San Juan Cancuc en pobreza de patrimonio) presentan porcentajes de población en edad laboral de $46.76,51.98$ y $48.31 \%$, respectivamente. En el municipio mejor clasificado en todos los indicadores, Tuxtla Gutiérrez, hasta $67.02 \%$ de la población está comprendida entre 15 y 64 años de edad, porcentaje que es el más alto de todo el estado.

Mientras que la composición por edades guarda una estrecha relación con los indicadores de desarrollo, marginación, rezago social y pobreza, otras características demográficas, como la composición por género de la población, presentan coeficientes muy bajos. El índice de masculinidad, que expresa el tamaño de la población masculina respecto a la femenina, muestra unos coeficientes de correlación prácticamente nulos. Ni los municipios con índices de masculinidad más bajos: Frontera Comalapa (90.47\%), Tapalapa (90.59\%) o Zinacantán (91.23\%); ni aquellos con índices más altos: Sunuapa (107.35\%), Montecristo de Guerrero (106.31\%) o Chiapilla (105.77\%), son los que presentan indicadores de desarrollo o de pobreza mayores o menores. Atendiendo a los signos de los coeficien- 
tes, se encuentra que los municipios con mayor porcentaje de población masculina tienden a presentar un IDH ligeramente más bajo e índices de marginación y rezago social ligeramente más altos aunque, como se ha hecho notar, la relación es muy débil en cualquiera de los casos a la vista de los valores mínimos de los coeficientes. Si en lugar del índice de masculinidad para el total de la población se considera el índice de masculinidad para los que tienen entre 15 y 39 años de edad, ${ }^{13}$ los coeficientes de correlación aumentan, aunque siguen siendo bajos: -0.315 para el IDH, 0.288 para el índice de marginación, 0.274 para el rezago social, 0.166 para los indicadores de pobreza alimentaria y de capacidades, y 0.162 para la pobreza de patrimonio. En cualquier caso, apenas existe relación entre la composición por género de las poblaciones y sus niveles de marginación, pobreza y desarrollo, hecho que se explica por la acción simultánea de dos fuerzas que se compensan mutuamente. Por un lado, se puede observar que las poblaciones femeninas tienden a presentar tasas de alfabetización y asistencia escolar más bajas, menores ingresos, así como otras características que actúan en detrimento de los indicadores de desarrollo humano, pobreza o marginación (PNUD, 2008: 10). Por otra parte, las poblaciones que residen en áreas rurales, en comparación con las urbanas, tienden a padecer esos mismos problemas. Debido a ello, la emigración femenina del campo a las ciudades diluye las menores cifras de bienestar de las mujeres en las mayores de las zonas urbanas, hasta el punto de revertir, como es el caso, el sentido de las relaciones que cabría esperar entre tasas de masculinidad y desarrollo. La emigración femenina en busca de empleos en el sector terciario explica que Tuxtla Gutiérrez, Tapachula y San Cristóbal de las Casas, los únicos tres municipios de Chiapas con núcleos urbanos que superan los 100,000 habitantes, sean el quinto, octavo y undécimo con mayores porcentajes de población femenina, lo que no impide que clasifiquen muy bien en todos los indicadores de bienestar incluidos en este estudio. La emigración masculina hacia otras entidades federativas del país o a Estados Unidos no parece haber tenido incidencia alguna en la relación comentada, lo que se debe a la ausencia de una relación clara entre tasas de emigración e indicadores de desarrollo en el ámbito municipal, al menos en Chiapas (Villafuerte y García, 2006: 124-127; 2008: 55-56).

Para analizar si la composición étnica tiene algún efecto destacado en los distintos indicadores que se consideran, se recurrió a dos variables que permiten aproximar esta característica: el porcentaje de población que habla

\footnotetext{
${ }^{13}$ Se eligió este rango de edades porque es el de mayor intensidad reproductiva, en el que se forman las familias y en el que se definen gran parte de las posibilidades futuras de las personas al englobar los últimos estadios de la formación académica y los primeros de inserción al mercado laboral.
} 
lengua indígena (cuadro 2) y el porcentaje de población que únicamente habla lengua indígena. Para ambas variables, los coeficientes de correlación que se obtienen son altos y muy similares: -0.765 y -0.709 para el IDH, 0.695 y 0.665 para el índice de marginación, y 0.731 y 0.689 para el índice de rezago social, respectivamente. ${ }^{14}$ Estos valores indican que en aquellos municipios donde reside mayor porcentaje de población que habla lengua indígena, o que sólo habla lengua indígena, el nivel de desarrollo es menor y la marginación, el rezago social y la pobreza son claramente mayores, circunstancia que ya se ha hecho notar en otros estudios (CDI-PNUD, 2006: 19). Las variables que aproximan la composición étnica de la población también guardan una fuerte relación con las que resumen la estructura por edades. Coeficientes de -0.673 y -0.574 indican que los municipios con más alto porcentaje de indígenas tienden a presentar poblaciones más jóvenes, lo que se explica por sus mayores tasas de mortalidad y su elevada fecundidad. Los municipios que presentan porcentajes más altos de población que habla lengua indígena -Chalchihuitán (99.93\%), Santiago el Pinar (99.90\%), Aldama (99.88\%), Mitontic (99.75\%) y San Juan Cancuc (99.74\%)- son los que tienen menor población relativa en edad de trabajar: Chalchihuitán es el octavo con menor porcentaje de población entre 15 y 64 años de edad (49.39\%), Santiago el Pinar es el de menor porcentaje de todo Chiapas (46.76\%), Aldama es el quinto (48.82\%), Mitontic el noveno $(49.87 \%)$ y San Juan Cancuc el tercero (48.31\%). Estos municipios, formados casi sólo por población indígena, esencialmente joven, son los peor situados en los índices de desarrollo humano, marginación, rezago social y pobreza.

La relación entre la composición étnica, la estructura de edades y los diferentes indicadores considerados es alta. En principio, se podría pensar que el tamaño de la población de los municipios también puede ser una variable importante en el proceso de crecimiento económico y desarrollo debido a la generación de economías de escala. No obstante, más allá de las grandes ciudades, no existe una relación clara entre el número de habitantes de cada municipio y los índices de desarrollo, marginación o rezago social; ni siquiera expresando el número de habitantes en relación con la superficie de los municipios. De hecho, la densidad poblacional presenta coeficientes incluso más próximos a anularse (cuadro 2). Esto se debe a que existen municipios con altas densidades de población tanto entre los que tienen, por ejemplo, un IDH alto (Tuxtla Gutiérrez, Tapachula o San Cristóbal de las Casas), como bajo (Mitontic, Chamula o

${ }^{14}$ Los valores del coeficiente de correlación por rangos de Spearman entre el porcentaje de población que habla lengua indígena y los distintos indicadores de pobreza se encuentran en el cuadro 2. Para el porcentaje de población que únicamente habla lengua indígena y los indicadores de pobreza alimentaria, pobreza de capacidades y pobreza de patrimonio, los coeficientes son: $0.656,0.658$ y 0.644 , respectivamente. 


\section{Cuadro 3 \\ Valores del coeficiente de correlación de Spearman para los índices de desarrollo humano, marginación, rezago social y pobreza}

\begin{tabular}{|c|c|c|c|c|c|c|}
\hline & $\begin{array}{c}\text { Desarrollo } \\
\text { bumano }\end{array}$ & Marginación & $\begin{array}{l}\text { Rezago } \\
\text { social }\end{array}$ & $\begin{array}{c}\text { Pobreza } \\
\text { alimentaria }\end{array}$ & $\begin{array}{l}\text { Pobreza de } \\
\text { capacidades }\end{array}$ & $\begin{array}{l}\text { Pobreza de } \\
\text { patrimonio }\end{array}$ \\
\hline $\begin{array}{r}\text { Desarrollo } \\
\text { humano }\end{array}$ & 1 & & & & & \\
\hline Marginación & -0.936 & 1 & & & & \\
\hline Rezago social & -0.936 & 0.958 & 1 & & & \\
\hline $\begin{array}{l}\text { Pobreza } \\
\text { alimentaria }\end{array}$ & -0.818 & 0.822 & 0.881 & 1 & & \\
\hline $\begin{array}{l}\text { Pobreza de } \\
\text { capacidades }\end{array}$ & -0.819 & 0.823 & 0.880 & 0.998 & 1 & \\
\hline $\begin{array}{l}\text { Pobreza de } \\
\text { patrimonio }\end{array}$ & -0.816 & 0.819 & 0.874 & 0.988 & 0.994 & 1 \\
\hline
\end{tabular}

Fuente: Elaboración propia.

Aldama), como medio (El Porvenir o Yajalón). ${ }^{15}$ No parece que el tamaño ni la densidad de las poblaciones sean variables relacionadas con los indicadores considerados.

En el cuadro 3 se muestra la existencia de correlaciones relativamente elevadas entre los índices de desarrollo humano, marginación, rezago social y las diferentes categorías de pobreza. Como se ha visto a lo largo del análisis, todos estos indicadores tienden a clasificar de manera semejante a los distintos municipios. Los más desarrollados son los que presentan menor marginación, menos rezago social y menor pobreza, tanto alimentaria, de capacidades, como de patrimonio. La dinámica semejante de todos estos indicadores, junto con la estrecha relación que mantienen con la composición étnica y los cambios en la estructura de edades, corresponde con el planteamiento de Chenery y Syrquin (1975) que explica el desarrollo como un proceso integral que afecta diversas variables. La causación circular negativa (Myrdal, 1979) estaría detrás del escaso progreso observado en algunos municipios, fundamentalmente habitados por población indígena, que aún presentan estructuras de edades propias de las primeras etapas de la transición demográfica junto a valores de desarrollo bajos y de marginación, rezago social y pobreza altos. Frente a esta situación, la causación circular positiva habría dado lugar a que un cambio beneficioso en alguna de las variables hubiese favorecido la modificación de las otras, reforzando, a su vez, el cambio de la primera, "lo

\footnotetext{
${ }^{15}$ Todos estos municipios se encuentran entre los 20 con densidades de población más altas en el estado de Chiapas.
} 


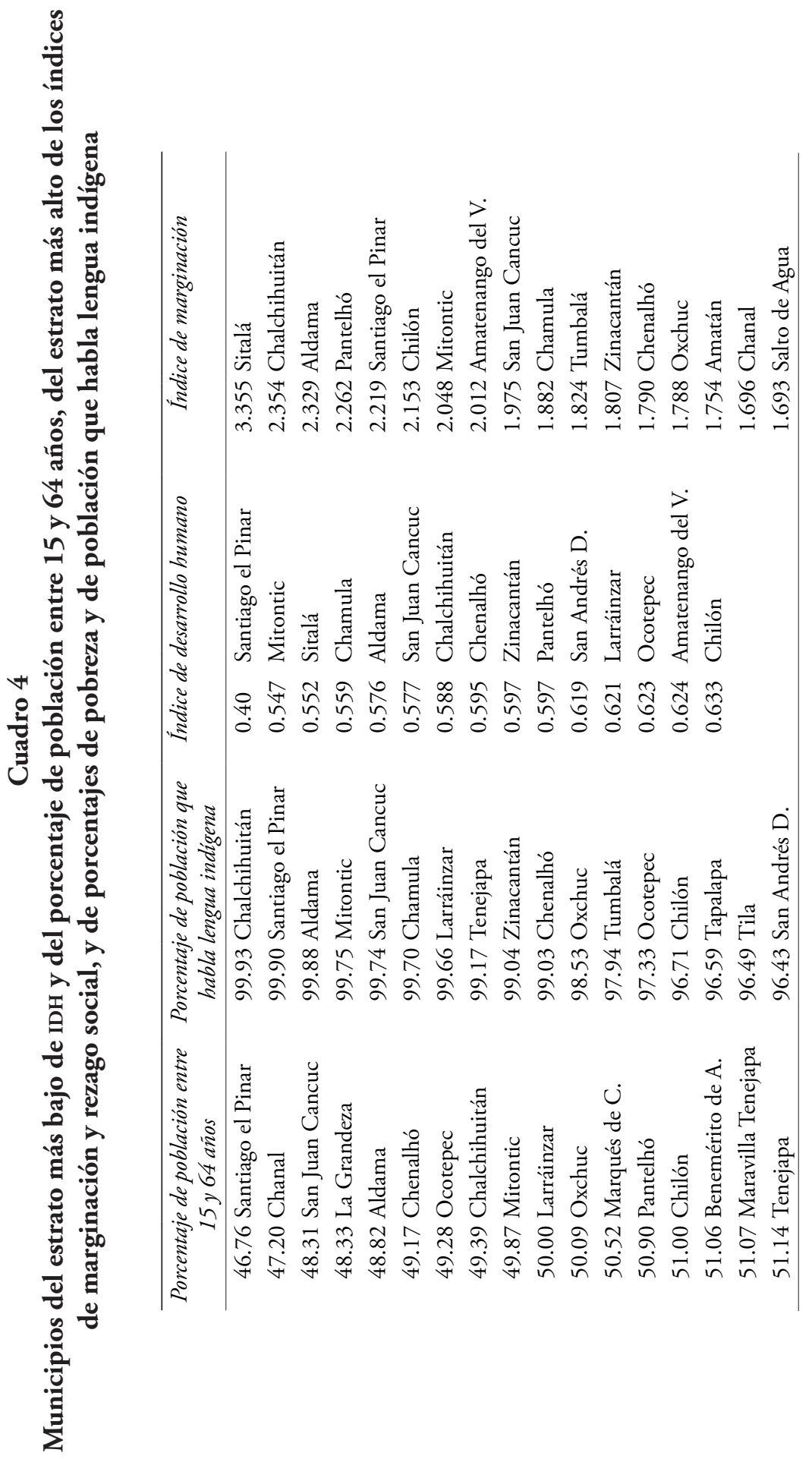




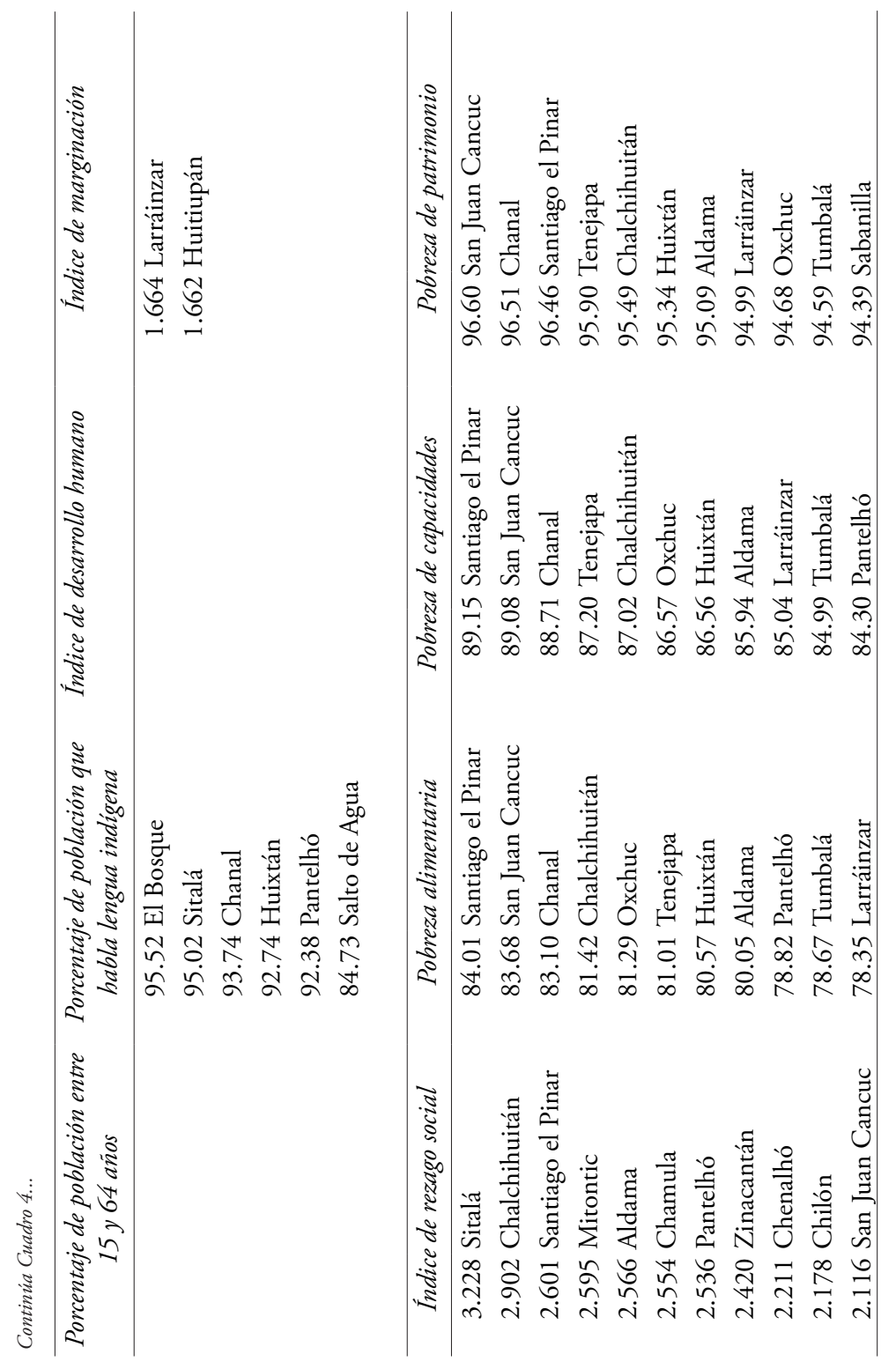




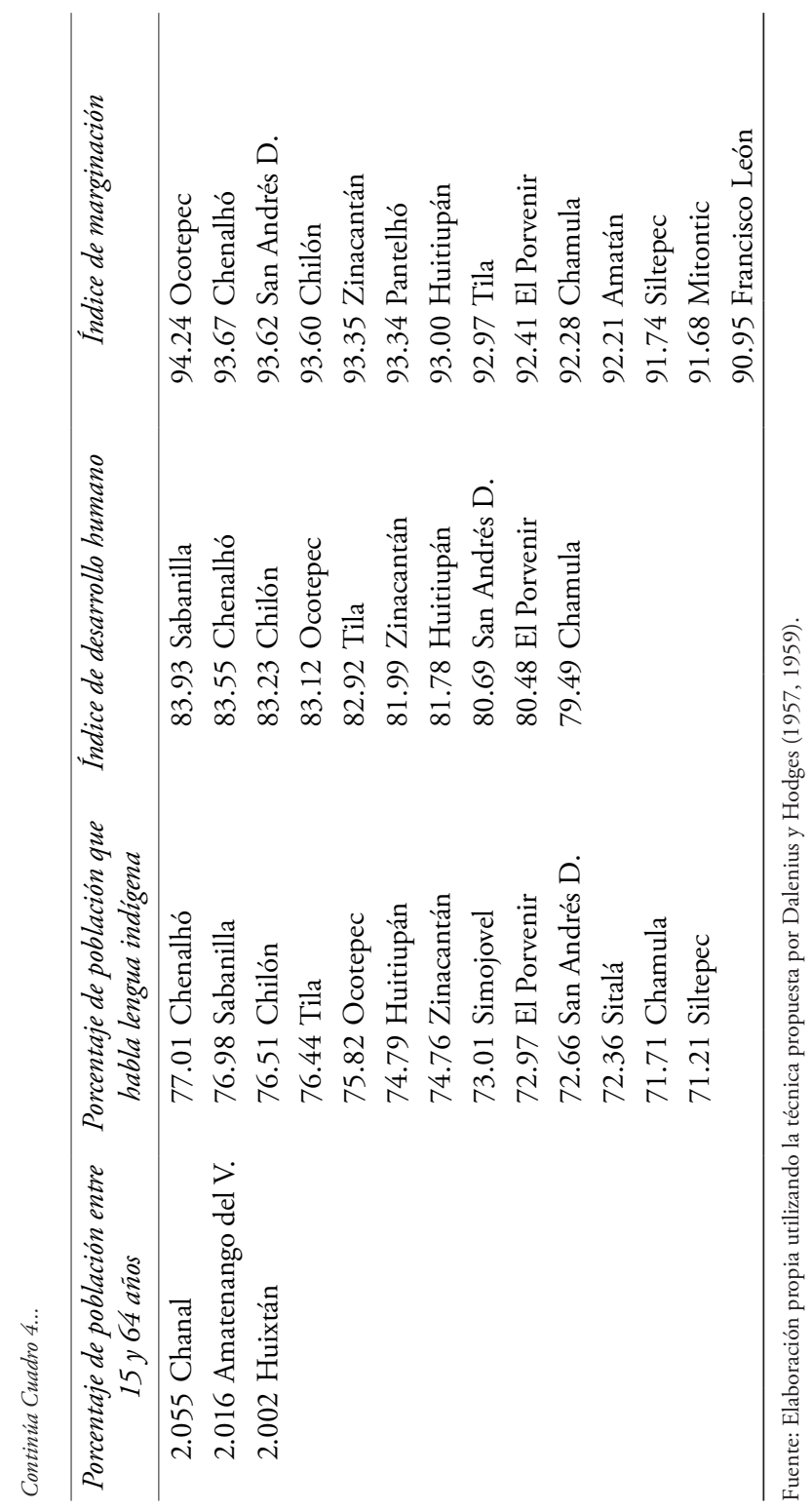


que iniciaría un proceso acumulativo de interacción mutua en el cual el cambio experimentado por un factor estaría apoyado de manera continua por la reacción del otro factor, y así sucesivamente en forma circular" (Myrdal, 1979: 28). En estos municipios habría actuado una espiral virtuosa provocando el cambio simultáneo de todas las variables.

$\mathrm{Al}$ conocer la relación existente entre los distintos indicadores y sabiendo que los municipios con mayor porcentaje de población indígena son los que presentan menor tamaño relativo de población en edad de trabajar, menor grado de desarrollo humano y mayor marginación, rezago social y pobreza, a continuación se procede a identificar y localizar estos municipios con problemas que no consiguen alcanzar una dinámica favorable capaz de guiar su desarrollo y su crecimiento económico. Para ello se segrega a los distintos municipios en cinco grupos de manera independiente para cada una de las variables analizadas, utilizando el método de estratificación univariante propuesto por Dalenius y Hodges (1957, 1959). ${ }^{16}$ En el cuadro 4 se indican los municipios situados en el peor estrato para los índices de desarrollo humano, marginación y rezago social, así como los que presentan porcentajes más bajos de población entre 15 y 64 años y más altos de población indígena y de pobreza alimentaria, de capacidades y de patrimonio. Como se observa, hay siete municipios que figuran en todas las clasificaciones: Aldama, Chalchihuitán, Chenalhó, Pantelhó y Santiago el Pinar, de la región Altos, y Chilón y San Juan Cancuc, de la región Selva. A estos se pueden añadir otros cuatro municipios que sólo están ausentes en una de las clasificaciones: Chamula, Chanal, Larráinzar y Zinacantán, todos ellos de la región Altos; y tres más presentes en seis de las ocho series: Mitontic y Oxchuc, de la región Altos, y Ocotepec, de la región Centro. Todos ellos comparten niveles muy bajos en el índice de desarrollo humano, muy altos en los indicadores de marginación, rezago social y pobreza, y poblaciones jóvenes, constituidas, fundamentalmente, por indígenas.

La figura III facilita la localización geográfica de los municipios de Chiapas una vez clasificados según los valores de los índices y de las variables consideradas. Como se puede observar, y como se ha comentado, apenas existen diferencias en los resultados obtenidos a partir de los dis-

${ }^{16}$ El Conapo (2006) emplea esta misma técnica de estratificación óptima para los municipios de Chiapas, pero en relación con todos los demás municipios del territorio mexicano. De esta forma, obtiene que 47 de los 118 municipios de Chiapas presentan un nivel de marginación muy alto; 64 nivel alto; cinco nivel medio (Arriaga, Comitán de Domínguez, Huixtla, San Cristóbal de las Casas y Tapachula); uno nivel bajo (Reforma), y uno nivel muy bajo (Tuxtla Gutiérrez). En este caso, la metodología de estratificación se aplica únicamente a los municipios de Chiapas, pero se extiende al resto de variables que han resultado relevantes en el análisis de correlación: porcentaje de población entre 15 y 64 ańos, porcentaje de población que habla lengua indígena, índice de desarrollo humano, índice de rezago social y las tres categorías de pobreza, además del índice de marginación. 


\section{Figura III}

\section{Localización de los municipios clasificados según distintos indicadores}
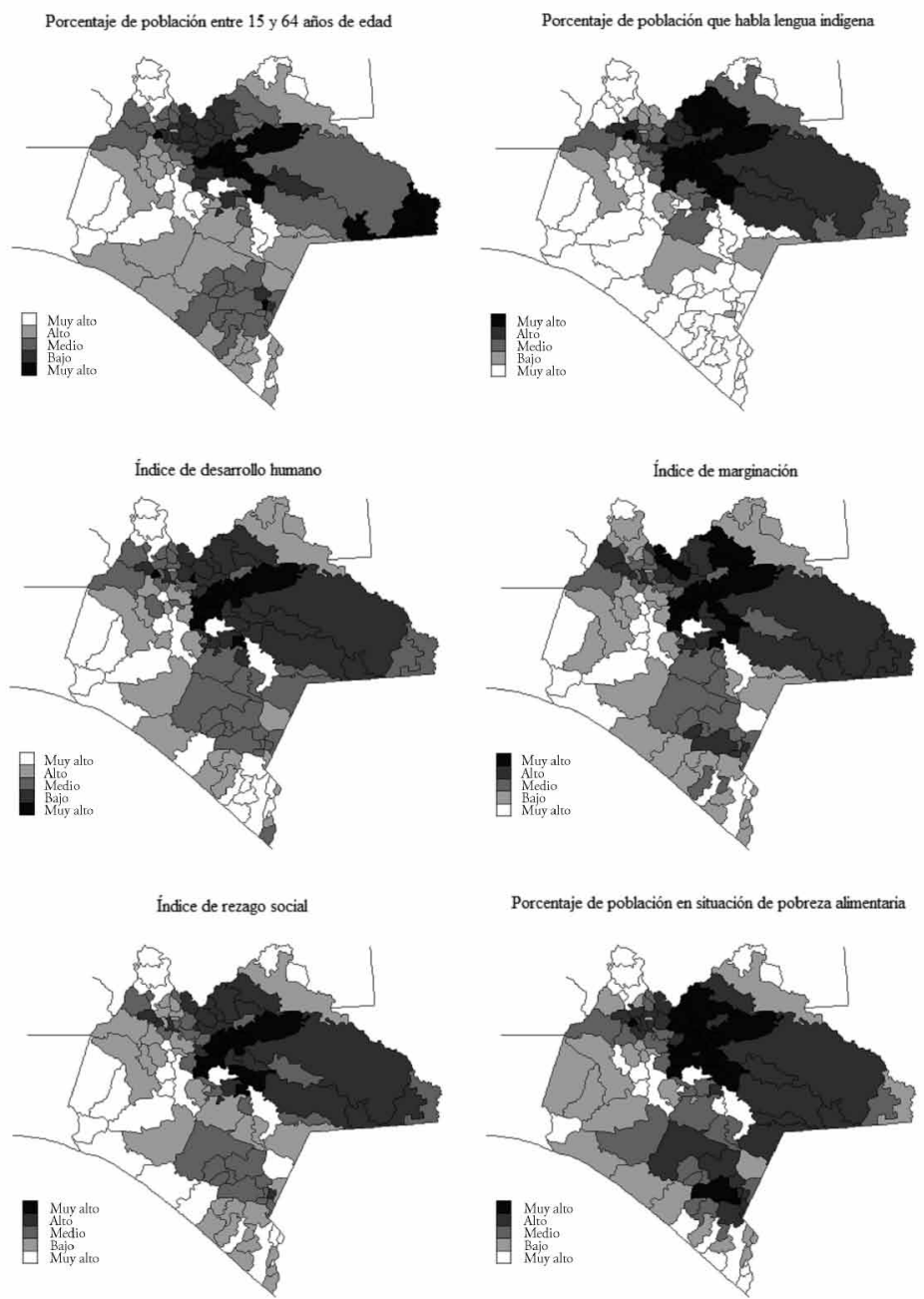

Fuente: Elaboración propia utilizando la técnica propuesta por Dalenius y Hodges $(1957,1959)$.

tintos indicadores. Los municipios peor situados en el índice de desarrollo humano son los que presentan grados de marginación, rezago social y pobreza más severos, un menor porcentaje de población en edad de trabajar y una mayor proporción de población que habla lengua indígena, y casi todos ellos se concentran en las regiones Altos y Selva. En municipios como Chenalhó, por elegir uno de los que están presentes en todas 
las clasificaciones del cuadro 4, el 99\% de la población habla lengua indígena ( $41 \%$ sólo habla lengua indígena, lo que limita sus posibilidades de comunicación y progreso) y menos de la mitad de los residentes (49\%) se encuentra entre 15 y 64 años de edad; $48 \%$ tiene menos de 15 ańos y sólo 3\% supera los 64; el índice de desarrollo humano (0.595) refleja condiciones semejantes a las de países como Camboya (0.598) (PNUD, 2007: 233), muy alejadas de las de México en su conjunto (0.820) e, incluso, de las de Chiapas (0.730) (PNUD, 2009: 81); ${ }^{17}$ el índice de marginación sitúa al municipio en el puesto 2,349 de los 2,454 de la República Mexicana; en rezago social ocupa la posición 2,404; la pobreza alimentaria afecta a $77 \%$ de los residentes, esto es, de acuerdo con la definición del Coneval, 77\% de la población de Chenalhó no tiene capacidad para obtener una canasta básica alimentaria aun haciendo uso de todo su ingreso en comprar sólo los bienes de dicha canasta; la pobreza de capacidades alcanza a $84 \%$ de los habitantes y la de patrimonio a $94 \%$, lo que implica que sólo $6 \%$ tiene ingresos suficientes para adquirir la canasta alimentaria básica y realizar los gastos necesarios en salud, vestido, vivienda, transporte y educación. Otros municipios, como Aldama, Chalchihuitán, Chilón, Pantelhó o San Juan Cancuc presentan condiciones incluso más preocupantes.

$\mathrm{Al}$ menos en parte, lo abultado de estas cifras de pobreza se explica por las deficiencias que Renshaw y Wray (2004) encuentran en la estimación y aplicación de líneas de pobreza homogéneas para un territorio tan amplio y heterogéneo como el mexicano. Estos autores argumentan, por ejemplo, que en el medio rural es difícil calcular los requerimientos y todos los ingresos del hogar, ya que deben evaluarse "los beneficios nomonetarios y la seguridad alimentaria derivada de los cultivos de subsistencia, de la caza, pesca, la carne de los animales domésticos o la leña" (p. 10). Si bien el Coneval diferencia entre zonas urbanas y rurales al estimar las líneas de pobreza, no establece ninguna distinción adicional, considerando las mismas líneas para todas las poblaciones rurales de México con independencia de sus costumbres, condiciones climáticas, acceso a fuentes naturales de agua, etcétera. Ello lleva a que $75.85 \%$ de los residentes en los 23 municipios de Chiapas con mayor porcentaje de indígenas se sitúen por debajo de la línea genérica de pobreza alimentaria, esto es, ni siquiera utilizando todos sus ingresos son capaces de costear la canasta básica alimentaria, de manera que les es completamente imposible sufragar los gastos de salud, vestido, vivienda, transporte y educación. El

\footnotetext{
${ }^{17}$ Cabe advertir que los valores calculados para el IDH en el ámbito nacional o regional no son estrictamente comparables con los obtenidos en el ámbito municipal, ya que en su cómputo se utilizan variables diferentes, como la esperanza de vida al nacimiento, que en el ámbito municipal se reemplaza por la tasa de supervivencia infantil (PNUD, 2009: 448).
} 


\section{Cuadro 5}

Valores del coeficiente de correlación de Spearman para los porcentajes de población entre 15 y 64 años de edad (1) y de población que habla lengua indígena (2) respecto de las componentes de los índices de desarrollo humano, marginación y rezago social

\begin{tabular}{rrl}
\hline (1) & (2) & \multicolumn{1}{c}{ Variables componentes de los indices de desarrollo humano, } \\
marginación y rezago social
\end{tabular}


porcentaje de población en situación de pobreza de capacidades en estos 23 municipios considerados de manera conjunta alcanza $82.62 \%$, mientras que la pobreza de patrimonio se eleva hasta 93.32 por ciento.

Los indicadores de necesidades básicas insatisfechas (IDH, índice de marginación e índice de rezago social) aportan información adicional sobre las causas de esta situación, ya que permiten un análisis más detallado a partir de sus distintos componentes. En el cuadro 5 se presentan los valores del coeficiente de correlación de cada una de las variables que intervienen en el cómputo de estos índices con respecto a las características demográficas que se encontraron relevantes: estructura de edades y pertenencia étnica (cuadro 2). Como se puede observar, de las cuatro variables que forman parte del IDH, sólo la tasa de asistencia escolar parece mantener una relación débil con las características demográficas señaladas. La tasa de mortalidad infantil tiende a ser mayor en los municipios con poca población en edad de trabajar así como en aquellos con altos porcentajes de población indígena. De modo análogo, la tasa de alfabetización de adultos y el ingreso por habitante guardan relación con la composición étnica y por edades de las poblaciones.

Las variables que integran los índices de marginación y rezago social consideran cuestiones más específicas, por ejemplo, el porcentaje de viviendas particulares habitadas que no disponen de excusado o sanitario que, en este caso, no guarda relación con los factores demográficos; o el porcentaje de viviendas particulares habitadas que no disponen de refrigerador que, por el contrario, tiene una incidencia diferencial muy importante en virtud de las cohortes de edad dominantes y de la condición étnica. Otras variables que presentan correlaciones muy altas con las características demográficas son los porcentajes de población analfabeta de 15 años o más, ocupantes en viviendas con piso de tierra y viviendas particulares habitadas que no disponen de lavadora. Aunque la presencia de condicionantes culturales en estas correlaciones es innegable, ${ }^{18}$ también lo es la situación de pobreza extrema y bienestar mínimo detectada en un buen número de municipios de Chiapas.

\section{Conclusiones}

Como se ha argumentado, el desarrollo es un proceso integral que implica modificar un buen número de variables que afectan no sólo la acumulación y asignación de recursos en la vida económica, sino también las relaciones sociales y las características demográficas de las poblaciones. No

\footnotetext{
${ }^{18}$ Renshaw y Wray argumentan que "comparar la sociedad indígena con el resto de la sociedad nacional en términos de ingresos, escolaridad o saneamiento básico es injusto, ya que estos son indicadores propios de la sociedad nacional que no tienen la misma relevancia para los indígenas" (2004: 1).
} 
es posible distinguir entre variables causa y variables efecto, ya que el desarrollo se presenta como un proceso de causación acumulativa en el que la dinámica de unos indicadores retroalimenta a otros y estos, a su vez, favorecen el cambio de los primeros. La explicación del desarrollo, de la reducción de la pobreza y, en definitiva, de las diferencias observadas entre los distintos municipios de Chiapas ha de tener en cuenta esta circunstancia; debe ser, por tanto, una explicación integral que considere no sólo los indicadores intermedios del desarrollo, de la marginación o del rezago social de manera aislada, sino todos los factores económicos, sociales y demográficos que intervienen y se interrelacionan en el proceso.

A lo largo del presente estudio se ha comprobado que la estructura de edades y el porcentaje de población que habla lengua indígena son variables que guardan una fuerte relación con los indicadores de bienestar considerados. Los municipios de Chiapas con menor porcentaje de población en edad laboral y con mayor porcentaje de residentes indígenas tienden a coincidir entre sí y con aquellos de menor desarrollo humano y mayor marginación, rezago social y pobreza. Si bien estos indicadores pueden estar subestimando las condiciones de vida de los indígenas dadas las metodologías que emplean en sus cálculos, la situación de estas poblaciones no es buena. Los cambios acontecidos en las últimas décadas no han favorecido a las unidades domésticas que practicaban una agricultura poco tecnificada. La apertura comercial iniciada a principios de la década de los ochenta y que culminó con la adopción del Tratado de Libre Comercio de América del Norte (TLCAN) a mediados de los noventa, ha deprimido los precios del maíz y el café desvalorizando el trabajo de los agricultores tradicionales, entre los que destacan los indígenas, que no han encontrado ninguna alternativa viable salvo la emigración a Estados Unidos, práctica inédita en Chiapas hasta hace dos décadas (Villafuerte y García, 2006; Pérez-Soria, 2009).

En el sur del país nunca se implementó un programa de industrialización fronteriza como sí se hizo en el norte a partir de 1965. Esto ha limitado sustancialmente las posibilidades de desarrollo de la región, donde en 2005 sólo $6.7 \%$ de la población activa laboraba en el sector manufacturero, frente al $17.2 \%$ del resto del país, siendo además, cada uno de estos trabajadores, cinco veces menos productivo que los de las demás entidades consideradas en conjunto. De modo semejante, el sector primario ha permanecido al margen de la modernización. En Chiapas, donde $41.8 \%$ de la población activa en 2005 aún permanecía en el sector primario, eran necesarios 2.4 trabajadores para producir el mismo valor que uno solo del resto del país. La apertura comercial sirvió para evidenciar la escasa competitividad productiva de Chiapas, lo que dio lugar a una reducción de la capacidad de obtener ingresos de buena parte de la 
población. Las políticas aplicadas para contrarrestar esta situación se han enfocado más a elevar los indicadores de bienestar que a enfrentar las causas estructurales que impiden su mejora. Así, por ejemplo, la acción del Programa Piso Firme ha reducido el porcentaje de viviendas con piso de tierra y, en consecuencia, los índices de rezago social y marginación, que incorporan esta variable, pero no ha dotado de nuevas fuentes de ingreso a las familias que, ante la escasez de recursos, siguen ampliando o construyendo viviendas nuevas con pisos de tierra.

En décadas recientes, ante el colapso parcial de la economía agrícola tradicional y la ausencia de alternativas en la región, la población ha tratado de garantizar su supervivencia a corto plazo en vez de adoptar estrategias de desarrollo a largo plazo. En un contexto en el que las alternativas se limitan a la agricultura intensiva en mano de obra o a la emigración para realizar trabajos de baja calificación, la educación de los hijos no se percibe como una ventaja, sino como un elemento que reduce temporalmente la capacidad productiva de la unidad doméstica y apenas tiene rendimientos a largo plazo. En ocasiones, las becas del Programa de Desarrollo Humano Oportunidades ni siquiera cubren el costo de traslado y alimentación de los alumnos que han de desplazarse durante varias horas por veredas de difícil tránsito para asistir a la escuela. En esas circunstancias, la productividad del trabajo y la capacidad para introducir innovaciones tienden a ser bajas, con lo que se perpetúa el círculo vicioso de la pobreza, dada la ausencia de incentivos para adoptar estrategias alternativas.

Teniendo en cuenta la interrelación que existe entre las variables analizadas, y a la luz de lo comentado, la recomendación fundamental que cabe realizar es que se deben impulsar medidas que no induzcan a la reproducción de los patrones actuales, sino que incidan en la raíz de los problemas, modificando la estructura productiva, claramente ineficiente, y permitiendo a las familias adoptar estrategias diferentes que, a su vez, aceleren la espiral de transformaciones que guían el proceso de desarrollo. Para ello será necesario tener muy en cuenta las particularidades de los pueblos indígenas, seriamente afectados por la extrema pobreza dadas sus dificultades de acceso a la salud (Sánchez et al., 2006), a la educación (INEE, 2006) y a los medios de producción.

\section{Agradecimientos}

Agradezco las sugerencias hechas a este trabajo por uno de los evaluadores anónimos, ya que contribuyeron sustancialmente a la mejora del texto. 


\section{Bibliografía}

Atkinson, Anthony Barnes (1974), "Poverty and income inequality in Britain", en Dorothy Wedderburn (ed.), Poverty, inequality, and class structure, Cambridge University Press, Cambridge, pp. 43-70.

Becker, Gary Stanley (1987), Tratado sobre la familia, Alianza, Madrid.

Becker, Gary Stanley y Harold Gregg Lewis (1973), "On the interaction between the quantity and quality of children", Journal of Political Economy, 81 (2), University of Chicago Press, Chicago, pp. 279-288.

Becker, Gary Stanley, Edward Ludwig Glaeser y Kevin Murphy (1999), "Population and economic growth", American Economic Review, 89 (2), American Economic Association, Pittsburgh, pp. 145-149.

Bloom, David, David Canning y Pia Malaney (2000), "Demographic change and economic growth in Asia", Population and Development Review, 26 (suplemento), Population Council, Nueva York, pp. 257-290.

CDI-PNud (Comisión Nacional para el Desarrollo de los Pueblos Indígenas-Programa de las Naciones Unidas para el Desarrollo) (2006), Informe sobre desarrollo humano de los pueblos indígenas de México 2006, CDI-PNUd, México.

Chenery, Hollis Burnley y Moises Syrquin (1975), Patterns of development, 1950-1970, Oxford University Press, Oxford.

Coale, Ansley Johnson (1988), “Demographic transition”, en John Eatwell, Murray Milgate y Peter Newman (eds.), The new palgrave: a dictionary of economics, Macmillan, Londres, pp. 793-796.

Coale, Ansley Johnson y Edgar Malone-Hoover (1958), Population growth and economic development in low-income countries. A case study of India's prospects, Princeton University Press, Princeton.

Conapo (Consejo Nacional de Población ) (2006), Indices de marginación, 2005, Conapo, México. 
Dalenius, Tore y Joseph Hodges (1957), "The choice of stratification points", Skandinavisk Aktuarietidskrift, 40, Almqvist \& Wiksell, Uppsala, pp. 198-203.

Dalenius, Tore y Joseph Hodges (1959), "Minimum variance stratification", Journal of the American Statistical Association, 54, American Statistical Association, Alejandría, pp. 88-101.

Davis, Kingsley (1937), "Reproductive institutions and the pressure for population", Sociological Review, 29 (3), Keele University, Keele, pp. 289-306. Reimpreso en 1997, Population and Development Review, 23 (3), Population Council, Nueva York, pp. 611-624.

Domínguez, Juana y Ana María Martín (2006), "Medición de la pobreza: una revisión de los principales indicadores", Revista de Métodos Cuantitativos para la Economía y la Empresa, 2, Universidad Pablo de Olavide, Sevilla, pp. 27-66.

Fries, James (1980), "Aging, natural death, and the compression of morbidity", New England Journal of Medicine, 303 (3), Massachusetts Medical Society, Waltham, pp. 130-135.

Galor, Oded y David Weil (1999), "From Malthusian stagnation to modern growth", American Economic Review, 89 (2), American Economic Association, Pittsburgh, pp. 150-154.

Galor, Oded y David Weil (2000), "Population, technology, and growth: from Malthusian stagnation to the demographic transition and beyond", American Economic Review, 90 (4), American Economic Association, Pittsburgh, pp. 806-828.

INEE (Instituto Nacional para la Evaluación de la Educación) (2006), Panorama educativo de México 2006. Indicadores del Sistema Educativo Nacional, INEe, México.

INEGI (Instituto Nacional de Estadística, Geografía e Informática) (2005), II Conteo de Población y Vivienda 2005, <www.inegi.org.mx>, 15 de abril de 2009.

INEGI (Instituto Nacional de Estadística, Geografía e Informática) (2008), Anuario estadístico: Chiapas, INEgi, Aguascalientes. 
Kakwani, Nanak (1986), Analyzing redistribution policies: a study using Australian data, Cambridge University Press, Nueva York.

Livi-Bacci, Massimo (2002), Historia mínima de la población mundial, Ariel, Barcelona.

Mason, Andrew (2007), "Demographic transition and demographic dividends in developed and developing countries", en ONU (ed.), United Nations expert group meeting on social and economic implications of changing population age structures, Mexico City, 31 August-2 September 2005, onu, Nueva York, pp. 81-101.

Modigliani, Franco (1986), "Life cycle, individual thrift and the wealth of nations", The American Economic Review, 76 (3), American Economic Association, Pittsburgh, pp. 297-313.

Myrdal, Gunnar (1979), Teoría económica y regiones subdesarrolladas, Fondo de Cultura Económica, México.

Notestein, Frank W. (1945), "Population: the long view", en Theodore W. Schultz (ed.), Food for the world, University of Chicago Press, Chicago, pp. 36-57.

Peláez, Óscar (2009), "La oportunidad (demográfica) de Chiapas”, en Jorge López-Arévalo (coord.), Globalización, migración y economía chiapaneca, Universidad Autónoma de Chiapas, Tuxtla Gutiérrez, pp. 113-126.

Pérez-Soria, Judith (2009), “Tres escenarios de la migración hacia Estados Unidos: el occidente, el centro y el sur de México”, en Jorge LópezArévalo (coord.), Globalización, migración y economía chiapaneca, Universidad Autónoma de Chiapas, Tuxtla Gutiérrez, pp. 73-84.

PNUd (Programa de las Naciones Unidas para el Desarrollo) (2007), Informe sobre desarrollo humano 2007-2008. La lucha contra el cambio climático: solidaridad frente a un mundo dividido, PNUD, Nueva York.

PNUd (Programa de las Naciones Unidas para el Desarrollo) (2008), Índice de desarrollo humano municipal en México 2000-2005, PNUD, México. 
PNUD (Programa de las Naciones Unidas para el Desarrollo) (2009), Indicadores de desarrollo humano y género en México 2000-2005, PNUD, México.

Renshaw, John y Natalia Wray (2004), "Indicadores de pobreza indígena”, borrador preliminar para el Banco Interamericano de Desarrollo (BID), Washington.

Rowntree, Benjamin Seebohm (1901), Poverty: a study of town life, Macmillan, Londres.

Sánchez, Héctor Javier, Marcos Arana y Alicia Ely Yamin (2006), Pueblos excluidos, comunidades erosionadas: la situación del derecho a la salud en Chiapas, México, Physicians for Human Rights-El Colegio de la Frontera Sur-Centro de Capacitación en Ecología y Salud para Campesinos, Cambridge.

Sen, Amartya (1983), "Poor, relatively speaking", Oxford Economic Papers, 35 (2), Oxford University Press, Oxford, pp. 153-169.

Thompson, Warren (1929), "Population”, American Sociological Review, 34 (6), American Sociological Association, Washington, pp. 959-975.

Townsend, Peter (1979), Poverty in the United Kingdom: a survey of household resources and standards of living, University of California Press, Berkeley.

Townsend, Peter (1993), The international analysis of poverty, Harvester Wheatsheaf, Nueva York.

Vallin, Jacques (1995), La demografía, Alianza, Madrid.

Villafuerte, Daniel y María del Carmen García (2006), "Crisis rural y migraciones en Chiapas", Migración y Desarrollo, 6, Red Internacional de Migración y Desarrollo, Zacatecas, pp. 102-130.

Villafuerte, Daniel y María del Carmen García (2008), "Algunas causas de la migración internacional en Chiapas", Economia y Sociedad, xIv (21), Universidad Michoacana de San Nicolás de Hidalgo, Morelia, pp. 41-58. 
Recibido: 29 de mayo de 2009. Reenviado: 28 de octubre de 2010. Aceptado: 24 de enero de 2011.

Óscar Peláez-Herreros. Es doctor por la Universidad de Cantabria, España; realizó estudios de experto universitario en métodos avanzados de estadística aplicada en la Universidad Nacional de Educación a Distancia (UNED) y de licenciatura en economía (especialidad en economía financiera) en la Universidad de Cantabria. Ha sido profesor asociado en el área de economía aplicada y ayudante en el área de métodos cuantitativos para la economía y la empresa de la Facultad de Ciencias Económicas y Empresariales de la Universidad de Cantabria. Entre 2008 y 2010 desarrolló su actividad docente e investigadora en la Facultad de Ciencias Sociales de la Universidad Autónoma de Chiapas. En la actualidad está adscrito al Departamento de Estudios Económicos de El Colegio de la Frontera Norte, su principal línea de investigación se centra en el análisis de los efectos que las dinámicas demográficas tienen en la economía y la sociedad. Ha colaborado en diversos proyectos de investigación y publicado artículos como: "Proyección a largo plazo de la esperanza de vida en España”, Estadística Española, 51 (170), Instituto Nacional de Estadística, Madrid, pp. 193-220 (2009); "Descripción y proyección de la esperanza de vida al nacimiento en México (1900-2050)", Estudios Demográficos y Urbanos, 24, 2 (71), El Colegio de México, México, pp. 469-492 (2009); "A state-level analysis of life expectancy in Mexico (1990-2006)", Journal of Biosocial Science, 42 (6), Cambridge University Press, Cambridge, pp. 815-826 (2010). 